\title{
Technological reliability of building of geotechnical structures
}

\author{
Taisiya Shepitko ${ }^{1, *}$, Sergei Kudryavtsev ${ }^{2}$, Svyatoslav Lutsky ${ }^{1}$, Viacheslav Zabolotny ${ }^{3}$, and \\ Viacheslav Kovshun ${ }^{2}$ \\ ${ }^{1}$ Moscow State University of Railway Engineering (MIIT), Minaevsky per., 2, Moscow, 127055, \\ Russia \\ ${ }^{2}$ Far Eastern State Transport University, Khabarovsk, Russia \\ ${ }^{3}$ LLC"Transstroymechanizatsiya», Galerny pr-d, 5 A, St. Petersburg, 199226, Russia
}

\begin{abstract}
Technological reliability is defined as the property of geotechnical structures to maintain the safety of the state and design and processing characteristics of the stability of the base and stability when changing development pressure during construction. The optimal technological mode should be completed as a steered step-by-step control process and properties amplification of soil characteristics by means of vibrodynamic loads. The management procedure of technological processes for the directed hardening of durability of earth roadbed on the weak bases is stated. The reasonable necessity of monitoring and forecasting the strainstress distribution of soils in the construction period is rationalized.
\end{abstract}

\section{Introduction}

The need for scientific justification and practical recommendations for the development and adaptation of innovative technologies in reliability growth of geotechnical structures at the construction stage is justified by a fundamental change in the nasal, established engineering surveys of soil characteristics and the formation of a new natural manufacturing unit. The relevance of the construction and technological stage increases in complex objects, especially in weak and collapsible soils, which are widespread in areas of modern buildings, including permafrost areas and high-speed lines.

In accordance with the Technical Regulations on Safety of Buildings and Structures reliability of the earth roadbed should be provided at all stages of the service life: engineering surveys, design, construction, reconstruction and exploitation. Technological reliability is defined, by analogy with the design reliability, as a property of the object to maintain during the construction of design and processing characteristics (a given rate of consolidation and soils strengthening) and safety (on the stability of the base and stability) when changing (regulation) of development pressures [1-5]. As a result of man-induced load impacts and deterioration of run-off flow, the drainage strip is degraded, the formation of new and the development of existing hazardous processes.

\footnotetext{
*Corresponding author: shepitko-tv@ mail.ru
} 


\section{Methods}

Among the promising scientific and methodological solutions, we note the high technology of strengthening weak soils, based on the regulation of process duty, which is proposed in MIIT IPSS, pioneered the use and designed and suitable for strengthening weak bases in the building period $[2,6]$.

The concept of high technology is proceed from sequenced increase in the strength characteristics and constancy of the soil at the baseline of the roadbed at the stages [3,6]: 1) cutting of soft soils in combination with drilling and blasting operations to replace the sand massif; 2) construction of drainage system in the base course (without clipping); 3) earth compaction impact and vibro-impact methods of technology regulation conditions; 4) deep hardening of weak soils by different types of piles; 5) the device foundation geogrill. At each stage (or combination of them), there is a directed technological regulation of production operations in real time, in this its fundamental difference from the operating systems.

High technology in interaction with structural measures improves soil properties and strength capacities of the roadbed subbase using drainage to reduce soil dampness. The optimal technological mode should be implemented as a controlled step-by-step process of control and improvement of soil characteristics by regulating vibration dynamic loads.

For technological reliability, it is necessary to determine the permissible (by safety factor) load, taking into account the vibration effect on the entire structure of the base in depth. Moreover, it is necessary to predict the load in time in each layer. The dynamic load from the vibroroller in the sand massif should not exceed the safe limit:

$$
K_{f} P_{k, t}\left(A_{t}, V_{t}, v_{t}\right) \leq \min \left[P_{t s}, P_{b}, P_{\max }\right]
$$

where $\mathrm{P}_{k, t}$-load, depending on the weight, speed of movement $\mathrm{V}_{t}$, amplitude of At, frequency $A_{t} v$ of the roller vibration and contact stiffness of the compacted layer in the "t» period of intensive technology; $\mathrm{P}_{\mathrm{ts}}$ - tensile strength of the sealing layer; $\mathrm{P}_{\mathrm{b}}$ - safe load capacity for the base course in shoving; $P_{\max }-$ maximum allowable vibroload by thixotropy; $K_{f}-$ load effect factor. Calculation of high technology modes should take into account the regulatory requirements of strength and stability of earth structures: on extreme loads and form alterations. When regulating technological parameters, the critical ultimate density of soils should be taken into account. The approximation, always special, of soils to the limit state (in terms of the safety factor) depends on the effective pressure, moisture load, loading speed, grading analysis, vibration action parameters. The purpose of technological regulation is the calculation of the most effective technological effects, in which the soil stabilization at the limit resistibility. Operating practice at exposure limit and loads should be maintained under the control of the soil and working conditions.

\section{Use in practice}

The technique of high technology has a positive experience, it has been implemented in areas of weak bases railway Karpogory-Vendinga, on the motorway bypass of the city of Perm, became part of the process procedure of the construction of the subgrade of the railway Obskaya-Bovanenkovo [1]. Technological efficiency of implementation was to improve the strength characteristics of soils and accelerate consolidation through the process control. The use of intensive (dynamic) soil compaction is also provided for the preparation of weak foundations of the roadbed in the design documentation for the construction of the high-speed line HSL-2.

The experimental application of the technology of soft soils strengthening in the base of the roadbed was carried out on the waterlogged area constructed on highway M-11 Moscow 
- St. Petersburg, 356- 357 km. in 2015 - 16 years. Excavation works were performed by LLC "Transstroymechanizatsiya". This technology has been developed in relation to shock-pulse compaction of weak bases [4].

One of the main reasons for the loss in reliability is the lack of uniformity of soils at the baseline. The practice and research studies of technology of weak soils cutting and replacement with a sandy massif in combination with drilling and blasting works on the construction of the highway M-11 in the wetland showed the need for geophysical diagnostics. Between the sand massif and the mineral bottom of the swamps remained the boundary layer of weak soil, which changes its properties under pore pressure and technological load for a long time. It is in this state of the multiarrayed, with variable characteristics, weak base that the risk of loss of stability arises due to the heterogeneity of the structure of the layers, which can lead to residual deformations in the boundary layer between the mineral bottom and the sand massif after replacement.

Compaction of the sand massif was carried out with the use of shock-pulse Impulse Compactor. Its onboard computer records the course of compaction in the form of a plan on which each position is applied with reference to the GPS coordinates. According to the results of the work performed on the sites, a register is formed, in which the specified numbers of sealing points, exact location of the Impulse compactor according to GPS navigation, the date of work, the number of pulses, the value of the last subsidence, the total subsidence of this compaction point on this date, the total subsidence of this compaction point for all dates and the subsidence curve for each pulse.

Strengthening of the upper zone of the sand massif was performed in hydrodynamic mode at the allowable load limits for all layers. The parameters and duration of the mode must be adjusted and controlled according to the change in the state of the bearing power of each layer. For this purpose, it is necessary to use the operation capacities of modern vibrorollers equipped with automated control systems for monitoring the compactness and stepless amplitude variation and vibratory frequency under high loads and extreme limit state of the soil. Process monitoring of vibration effect is differentiated for specific state of soil with the use of onboard monitoring system for compaction quality for the vibrorollers [9].

The technology regulations provide for the monitoring of physical-mechanical characteristics of the soil conditions at the control plot before the personnel shift and the amplitude control $\mathrm{A}$, frequency shift $v$, the traverse speed $v$ of the roller to the permissible strain at the depth of $\mathrm{h}: P_{\mathrm{t}}=f(A, v, v, h)$. A significant variation of soil characteristics indicates the possibility of risk of disturbance of the stability of the base in the process of consolidation by vibration. The risk calculation is carried out for the limit state at which the pressure and, accordingly, the stress in the soil from the roller exceeds the guarantee load. The risk of stability loss is the probability of a negative difference between the safe load capacity of $\mathrm{P}_{b}$ and the stresses from the process duty $\mathrm{P}_{t}$ (taking into account the pore pressure of $\mathrm{P}_{\mathrm{p}}$ and the backing layer of $\left.\mathrm{P}_{\mathrm{bl}}\right)$ :

$$
\mathrm{R}_{\mathrm{t}}=\mathrm{p}\left[\left(\mathrm{P}_{\mathrm{b}}-\mathrm{P}_{\mathrm{p}}\right)-\left(\mathrm{Pt}+\mathrm{P}_{\mathrm{bl}}\right) \mathrm{K}_{\mathrm{f}}\right]<0,
$$

The risk is regulated by the load reliability factor $\mathrm{K}_{\mathrm{f}}$, which is determined depending on the distributions of $\mathrm{P}_{b}$ and $\mathrm{P}_{t}$ for the level of significance of 0.95 . Thus, the load reliability factor $\mathrm{K}_{\mathrm{f}}$ should be established taking into account the permissible risk in the control plot and adjusted depending on the change in soil characteristics and incrimination of the permissible stress. It is proposed to reduce the probability of loss of bearing capacity of the base due to the consistent improvement of physical and mechanical characteristics (humidity, flow rate and density), achieved in the course of intensive soil compaction technology, and increasing both the safe load and the maximum permissible pressure from the roller. Regressional dependence of design strength of cohesive material from moisture gradient is written as:

$$
\mathrm{Q}=377.31-263.09 \mathrm{~W}-171.08 \mathrm{I}_{\mathrm{L}}
$$


where $\mathrm{Q}$-the calculated resistance, $\mathrm{kPa}$; W -humidity, f.u.; $\mathrm{I}_{\mathrm{L}}$ - flow-behavior index. The values of $\mathrm{P}_{\mathrm{p}}, \mathrm{P}_{\mathrm{b}}$ and $\mathrm{P}_{\mathrm{t}}$ are determined depending on the depth of the layer and the strength characteristics of the soil, which vary in each layer of the base in the technological cycle.

The reliability factor takes into account the possible deviation of the process duty and the efficiency of subgrade soil. The reasons for these deviations are: inaccuracy of engineering surveying at determining the characteristics of soils, insufficiently substantiated average values of the soil reliability factor, conditions of work and responsibility of the structure; changes in the boundaries of geological elements.

In order to determine the effective machine work modes of momentum puddling, providing the design objectives in density and soil consolidation of the roadbed subbase, parameter evaluations of the shock-pulse technology of the sand massif puddling is performed.

The analysis is based on the results of statistical manipulation of the onboard processing unit readings of the machine on the course of compaction in the area of the quality performance QP 3288-3289 of the highway M-11 from a sample collection of 235 measurements of shrinkage. As a matter of course, by use of the onboard computing system, technological monitoring was organized, which allowed to adjust the controlled features: the number of blows and location of the machine positions according to the achieved soil consistency and coefficient of impact. According to the results of the study of technological processes, the consolidated regressional dependences were established (superpositions of dependences on 48 statistical arrays, $\left.\mathrm{R}^{2}=0.91-0.93\right)$ of the current shrinkage $\mathrm{S}$ on the sweep counts $(x)$ at each of the 48 stops of the impulse compaction machine:

$$
\mathrm{S}=32.736 \mathrm{x}^{-0,449}
$$

the dependence is taken in the range of 1-24 beats;

$$
\mathrm{S}=24.262 \mathrm{x}^{-0,447}
$$

the dependence is taken in the range of $21-46$ beats.

To determine the assessment of the degree of compaction of soils, geophysical studies physical changes of specific electrical resistance and elastic waves' rate of spread. The site investigations was located on the road construction M-11 QP 3566 - QP 3568+70, crossing over the river Kolomenka. In the program of geophysical investigations, a challenge of scoring and effectiveness of the use of integrated technology were set.

1. Geophysical results have confirmed consistent stability augmentation and consolidation of the base. On the obtained seismic profiles of the increase in the velocities of transverse seismic waves, which indicates the occurred hardening of the soil and reducing moisture content.

2. According to the results of electrical exploration work, changes in the spatial distribution of the electrical resistivity were revealed, which indicates an increase in the degree of compaction and a decrease in soil moisture, as well as a reduction in areas related to weak and fluid soils of the embankment base.

3. On the georadar sections, obtained after blasting, there are changes in the structure of the wave electromagnetic field, which indicate that the sand embankment has become uniform and the soil moisture of the embankment has decreased.

\section{Conclusions}

1. Technological reliability of geotechnical structures as a property of the object to maintain a given rate of consolidation and hardening of soils should be provided during construction. When regulating development pressure, the principle of allowable load limit should be observed: the manmade load should be regulated in the maximum size to the limit state of 
the soil, but not more than the permissible, safe value for the stability of the base, tixotropy of the soil and the stability of the erected part of the structure.

2. The state of the foundations of the roadbed in the construction period is considered as the functioning of the natural and technical system of soils and technological loads with random characteristics and a certain probability of failure. The method of reliability improvement is developed in relation to the technological regulations of strengthening the weak Foundation of the embankment in the every-shift mode of load parameters regulation (weight, forcing force of the vibro eddy rollers, vibration effects, speed and number of passes of roller).

3. When calculating the loads it is proposed to take into account the anisotropic heterogeneity of soils. On the construction sites of the new highway M-11, the use of intensive technology has improved the stability of the base on weak soils. The efficiency of correlation between drilling and blasting and shock-pulse methods of compaction of the bases is established.

4. Managing the technological reliability of the grounds is to regulate the load and monitor its impact in real time. Unregulated loads increase the technological risk with intensive compaction of the base by increasing the probability of exceeding the load bearing capacity of the base especially at high power of weak soils.

\section{References}

1. S.Y. Lutsky, T.V. Shepitko, Construction of Railways in the North-M (LATMES, 2009)

2. S.Y. Lutsky, E.S. Ashpiz, D.V. Dolgov, Roadbed and method of its construction, Pat. No. 2273687 (2005)

3. S.Y. Lutskiy, T.V. Shepitko, A.Y. Burukin, Science in Cold and Arid Regions 9(3) (2017) DOI:10.3724/SP.J.1226.2017

4. C.Y.Lutsky, B.A. Sakun, Transport construction 8, 18-22 (2015)

5. S.Y. Lutskii, L.T. Roman, Soil Mechanics and Foundation Engineering 54-3, 187-191 (2017)

6. Recommendations for intensive technology and monitoring of earth structures construction on weak grounds (TIMR, Moscow, 2005)

7. N.A. Tsytovich, Soil mechanics (Higher school, Moscow, 1983)

8. L. Jiankun, P. Liyun, Cold Regions Science and Technology 58, 92-96 (2009)

9. R. Schreder, Compaction (Wirtgen Group HAMM AG, 2011) 